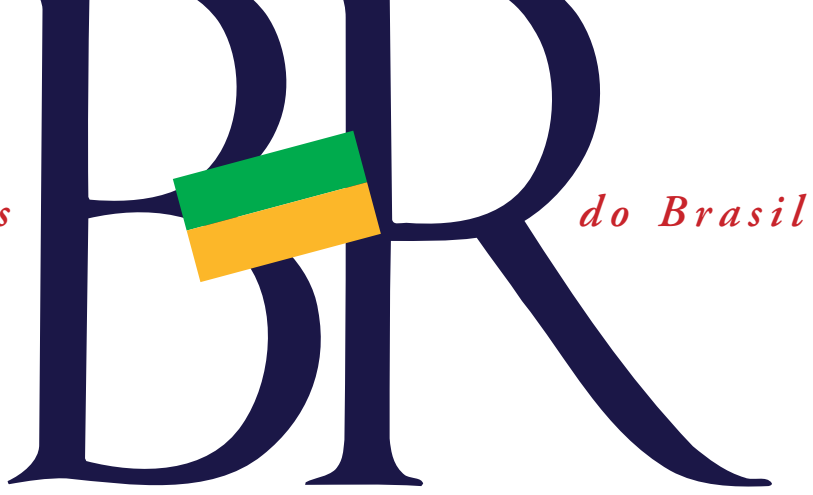

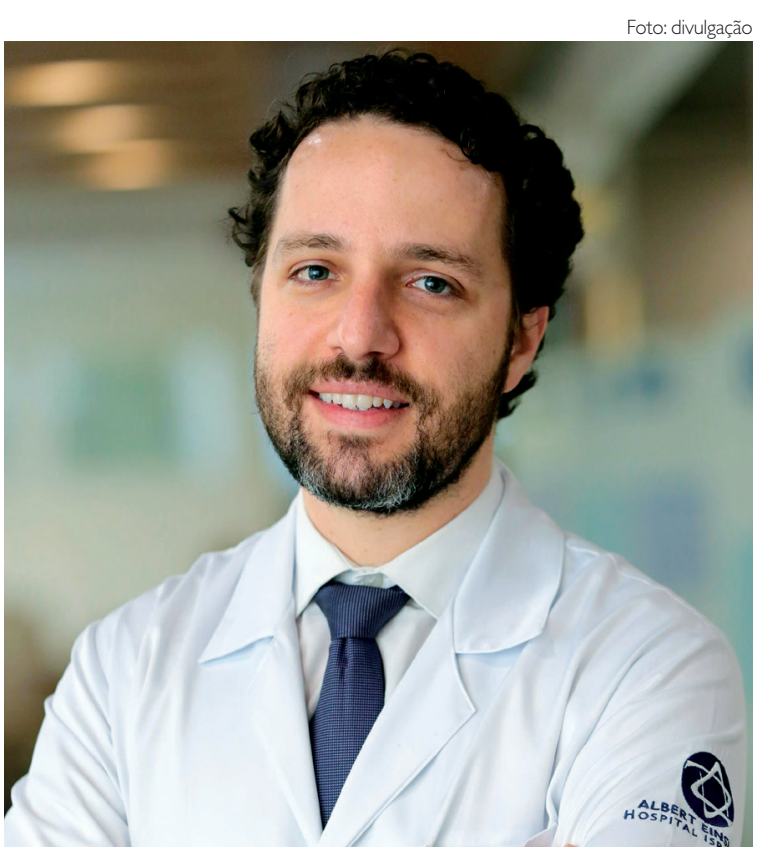

Diagnóstico e tratamento precoces do câncer são desafios para o sistema de saúde no Brasil

Entrevista: Felipe Ades

\section{Uma receita para a inovação nas pesquisas sobre câncer}

Felipe Ades é médico formado pela Universidade Federal do Rio de Janeiro (UFRJ), com especialidade em oncologia clínica, pelo Instituto $\mathrm{Na}$ cional de Câncer (Inca). Passou cinco anos na Europa, onde adquiriu os títulos demestrepeloInstituto Gustave Roussy, em Paris, e de doutor (PhD) pelo Institut Jules Bordet, em Bruxelas. Suas pesquisas na área de oncologia incluem desde estudos em labora- tório, testes de novos medicamentos e políticas de saúde coletiva para prevenção e tratamento do câncer. Atualmente, Ades trabalha no Hospital Albert Einstein, em São Paulo. Para divulgar informaçōes sobre prevenção, diagnóstico e tratamento da doença, mantém o blog "Oncologia ontem hoje e amanhã", onde responde, pessoalmente, todas as dúvidas dos internautas. Nesta entrevista para a revista Ciência\& Cultura, ele fala sobre políticas de saúde pública para tratamento dessa doença. Segundo ele, o diagnóstico precoce e iniciar o tratamento rapidamente ainda são desafios para o sistema público de saúde no Brasil.

Ciência\&Cultura: Na área de oncologia, quais seriam os caminhos para reduzir o gap de inovação entre o que se produz na academia e na indústria e o que será efetivamente acessível aos pacientes, especialmente em relação a novos fármacos?

Felipe Ades Esse é um cenário complexo que envolve educação, regulamentação e organização. Temos um problema de educação básica, que começa no ensino fundamental e que impede nossa sociedade de ter cultura científica. Formamos analfabetos funcionais. Agora imagine, se não conseguem ler e escrever, como é que vão reconhecer a importância e a dinâmica da pesquisa, o que é produzir ciência e tecnologia? Com que ferramentas vão desenvolver capacidade de criticar a ciência? Por outro lado, nossa regulamentação é ruim, muito burocrática e com cargos técnicos sendo ocupados por pessoas indicadas e não por especialistas, sobretudo em órgãos públicos. No Conselho Nacional de Ética em Pesquisa (Conep), ligado ao Ministério da Saúde, por exemplo, até pouco tempo, não havia médicos para validar as pesquisas. Para piorar, a grande maioria dos nossos parlamentares não tem ideia do que é ciência. Então, os cientistas das universidades que pesquisam, como gostamos de brincar, por "amor à camisa", lutam contra os entraves burocráticos, por mudanças na legislação e agilização dos processos; mas têm que lidar com a falta de investimento na universidade (que está sucateada) e nos demais órgãos de pesquisa públicos. Para completar, não conseguimos realizar pesquisas colaborativas. Falta fomento, capital intelectual e organização. Recentemente, por meio de uma iniciativa chamada Lacog (Latin American Collaborative Oncology Group), liderada por um médico brasileiro, tentamos organizar essa questão, mas estamos muito atrás dos Estados Unidos e da Europa, que fazem isso desde a década de 1950. Entre os médicos sempre brincamos que, com esse cenário, não precisamos que ninguém nos atrapalhe; nós mesmos fazemos isso. 


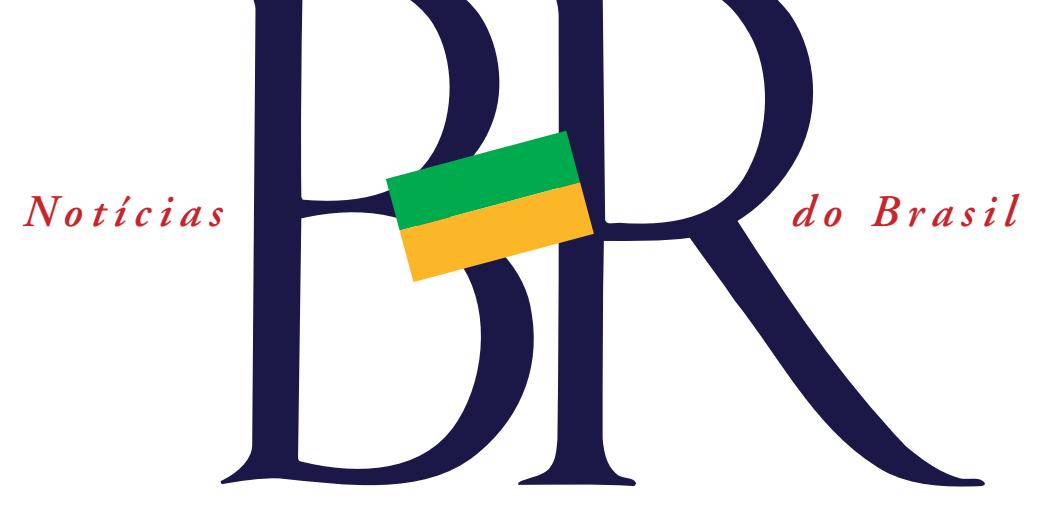

Ciência\&Cultura: E quais os caminhos para solucionar essas questões de legislação, formação intelectual e parcerias?

Do ponto de vista da comunidade científica, em curto prazo, precisamos nos abrir para colaborações com o mercado e agilizar processos burocráticos de regulamentação. A área de pesquisa em saúde ainda é, em geral, muito resistente a essa interação com a indústria. Temos tanta burocracia que não conseguimos entrar em estudos multicêntricos e internacionais; mesmo aqueles liderados por pesquisadores brasileiros. Isso seria crucial para formação de capital intelectual, de massa crítica. Nesse sentido, o mercado consegue se organizar de forma mais autônoma; atrai bons profissionais e utiliza metodologia mais eficiente. A academia fica para trás. É muito difícil hoje ser pesquisador e fazer pesquisa de qualidade no Brasil. Enquanto isso não acontece, precisamos aceitar, a indústria lidera. No mercado de pesquisa clínica, quem dita as regras é a indústria farmacêutica, que tem o protocolo e o dinheiro e decide o que vai ou não ser pesquisado. Precisamos participar dessas pesquisas, mostrar para o mundo que estamos aqui. Temos metade da população da Europa, não é possível não conseguirmos fazer pesquisa clínica; mesmo que seja para responder perguntas não tão relevantes para o nosso país, te- mos que participar. Por exemplo, os norte-americanos não têm câncer de colo-uterino. Como podem liderar pesquisas nessa área? Mas como não temos investimento e nem mesmo muita expertise, o primeiro passo é nos adequar aos protocolos ditados pela indústria norte-americana e formar capital intelectual. Com o tempo, teremos oportunidade de desenvolver pesquisas focadas nos nossos problemas, em nossa realidade. A situação ideal, ganha-ganha, seria pela parceria público-privada, todo mundo se beneficiaria: a academia pela produção científica e a indústria pela produção. Agora, do ponto de vista da sociedade como um todo, e não só na perspectiva de médico, em longo prazo, precisamos olhar para essa questão da educação com mais cuidado. $\mathrm{O}$ cidadão precisa entender sua saúde/doença, conhecer seu corpo e, principalmente, saber o que existe de disponível em prevenção, diagnóstico e tratamento.

Ciência\&Cultura: Você poderia falar sobre a real importância dos recentes avanços em diagnóstico molecular para indicar novas abordagens terapêuticas?

Há testes moleculares bem definidos e validados - disponíveis para saúde suplementar e particular, mas não para o SUS - e que são excelentes ferramentas para orientar casos específicos, personalizados; mas não podem ser replicados para toda a população. Nesse sentido, a comunidade científica precisa fazer seu papel, criando um banco de dados prospectivo para reforçar o nível de evidência, que hoje é baixo.

Ciência\&Cultura: É possível saber quem se beneficia, de fato, dessas técnicas? Quais os critérios para "escolher" para quem serão indicadas essas abordagens no Sistema Único de Saúde - SUS, onde mais de $60 \%$ dos casos de câncer estão em estágio avançado?

Falamos muito em medicina personalizada, mas acho que, hoje, o termo correto é medicina estratificada, que impóe escolher quem tem maior ou menor chance de tratamento. Isso desencadeia um panorama de incerteza sobre quem será, realmente, beneficiado. Os critérios estão sendo afinados, e isso é ótimo, um excelente caminho. Entretanto, há uma questão grave: há drogas fantásticas que são acessíveis a uma minoria da população do mundo, e não só no Brasil, por conta dos altos custos. E é uma equação que não fecha. Isso dá origem a fenômenos de judicialização, causando um choque entre o direito individual e o coletivo. Isso é uma discussão para a sociedade fazer. $\mathrm{Na}$ Europa, há uma conta de custo vs efetividade e existem órgãos no governo validando se aprovam, ou não, a droga. Entretanto, no Brasil, não temos maturidade para discutir 
